\title{
KỄT QUẢ PHẪU THUẬT BỆNH LÝ PHỒNG VÀ LÓC ĐỘNG MẠCH CHỦ
}

\section{Nguyễn Sinh Hiền*, Nguyễn Thái Minh*, Lê Quang Thiện*}

\section{TÓM TẮT}

32 bệnh nhân được phẫu thuật với 46,9\% phồng động mạch chủ, 53,1\% lóc động mạch chủ. Tuổi trung bình $52,8 \pm 14,1$, tỉ lệ nam/nữ 2,2/1.Thời gian cặp ĐMC trung bình là 125,4 \pm 47,6 phút, thời gian chạy máy trung bình là 173,0 $\pm 57,6$ phút. Phẫu thuật Bentall được thực hiện phần lớn chiếm $43,8 \%$. Tỷ lệ tử vong trong 30 ngày là $12,5 \%$. Chảy máu phải mổ lại $18,8 \%$, tổn thương thần kinh sau mổ chiếm 18,8\%. Tỷ lệ tử vong và biến chứng sau phẫu thuật điều trị bệnh lý phồng và lóc ĐMC là khả quan với kỹ thuật mổ và điều kiện gây mê hồi sức tại Bệnh viện Tim Hà Nội.

Tù khóa: Phồng động chủ, lóc động mạch chủ

\section{SUMMARY}

46,9\% aneurysm; $53,1 \%$ dissection. The mean age $52,8 \pm 15,3$; male/female 2,2/1. Mean aortic clamp time125,4 \pm 47,6 minutes; mean cardiopulmonary bypass time $173,0 \pm 57,6$ minutes. The Bentall procedure was performed $43,8 \%$. 30 days mortality was $12,5 \%$. Reoperation for bleeding 18,8\%; neurological complication $18,8 \%$. The result of these operations were acceptabe with the condition of surgery and anesthesis in Hanoi Heart Hospital.

Key words: Aneurysm aorta, dissection aorta.

\section{I. ĐẶT VẤN ĐỀ}

Bệnh lý phồng và lóc động mạch chủ (ĐMC) là bệnh lý rất nặng, phẫu thuật khó. Năm 1955. DeBakey thông báo ca phẫu thuật đầu tiên điều trị lóc ĐMC. Từ đó đến nay, có nhiều các nghiên cứu về bệnh lý này cũng như kết quả phẫu thuật từ các trung tâm tim mạch trên thế giới.

Tại Việt Nam, phẫu thuật phồng và lóc ĐMC được thực hiện đầu tiên tại Bệnh viện Việt Đức vào những năm 2000. Hiện nay, nhiều trung tâm phẫu thuật tim lớn trong nước đã triển khai thành công phẫu thuật này với kết quả ngày càng khả quan [1-2]

Tại Bệnh viện Tim Hà Nội,trong hai năm gần đây số lượng bệnh lý phồng và lóc ĐMC được mổ ngày càng lớn. Chúng tôi tiến hành nghiên cứu đánh giá kết quả bước đầu của phẫu thuật (PT) điều trị bệnh lý này.

\section{II. ĐỐI TƯợNG VÀ PHƯƠNG PHÁP NGHIÊN CỨU}

Hồi cứu tất cả các bệnh nhân (BN) phồng và/hoặc lóc động mạch chủ được phẫu thuật tại Bệnh viện Tim Hà Nội từ 1/2015 đến 6/2016. Không đưa vào nghiên cứu những hồ sơ của bệnh nhân có phẫu thuật những bệnh lý này ở đoạn ĐMC dưới cơ hoành.

Số liệu được xử lý bằng phần mềm SPSS 22.

\footnotetext{
* Bệnh viện Tim Hà Nội

Ngườ chịu trách nhiệm khoa học: TS. Nguyễn Sinh Hiền Ngày nhận bài: 10/02/2017 - Ngày Cho Phép Đăng: 10/03/2017 Phản Biện Khoa học: PGS.TS. Đặng Ngọc Hùng GS.TS. Lê Ngọc Thành
} 


\section{KẾT QUẢ}

\section{1. Đặc điểm bệnh nhân:}

Bảng 3.1. Đặc điểm bệnh nhân

$\begin{array}{lll}\text { Phồng } & \text { Lóc } & \text { Chung } \\ 15(46,9) & 17(53,1) & 32(100)\end{array}$

Đặc điểm trước mổ

Tuổi

$47,9 \pm 13,1 \quad 57,1 \pm 13,8 \quad 52,8 \pm 14,1$

Nam giói $n(\%)$

$11(50)$

11(50)

$22(68,8)$

Marfan n (\%)

6(40)

$3(17,6)$

$9(31,2)$

Đau ngục n(\%)

$5(33,3)$

$15(88,2)$

$20(62,5)$

Hơ chủ ( $\geq 2 / 4)$ n(\%)

$8(53,3)$

$6(35,3)$

$14(43,8)$

Tràn dịch màng tim n(\%)

0

$7(41,2)$

$7(21,9)$

Sốc $n(\%)$

$1(6,7)$

$1(5,9)$

$2(6,3)$

Mổ lạin(\%)

$2(13,3)$

$2(11,8)$

$4(12,5)$

\section{Đặc điểm trong mổ}

Phẫu thuật Bentall n(\%)

$9(60)$

$5(29,4)$

$14(43,8)$

Phẫu thuật Thay đoạn ĐMC lên n(\%)

0

$6(35,3)$

$6(18,8)$

Phẫu thuật Quai ĐMC n(\%)*

$1(6,7)$

$6(35,3)$

$7(21,9)$

Phẫu thuật khác n(\%) **

$5(15,6)$

Thời gian cặp ĐMC trung bình (phút)

$109,3 \pm 29,6$

$138,6 \pm 55,8$

$125,4 \pm 47,6$

Thời gian chạy máy trung bình (phút)

$155,5 \pm 38,5$

$188,5 \pm 47,1$

$173,0 \pm 57,6$

\section{Đặc điểm sau mổ}

Thời gian thở máy (giờ)

$$
61,6 \pm 61,3
$$

$97,6 \pm 84,9$

$80,7 \pm 75,9$

Thời gian điều trị (ngày)

$25,1 \pm 19,0$

$19,4 \pm 13,0$

$22,1 \pm 16,1$

*Phẫu thuật Quai ĐMC: thay toàn bộ hoặc 1 phần quai +/- Bentall hoặc ĐMC lên hoặc ĐMC xuống ** Phẫu thuật khác:1 ca Bentall + cầu vành LAD, 1 ca thay van chủ + ĐMC lên, 1 ca thay ĐMC xuống, 1 ca cắt khâu giả phồng ĐMC, 1 ca Thay ĐMC lên + cắm lại mạch vành 


\subsection{Kết quả sớm sau mổ}

Bảng 3.2. Các biến chứng sớm sau mổ

\begin{tabular}{|l|l|l|}
\hline Biến chứng & Số lượng & $\%$ \\
\hline Chảy máu mổ lại & 6 & 18,8 \\
\hline Tai biến mạch máu não & 6 & 18,8 \\
\hline Suy thận & 5 & 15,6 \\
\hline Suy đa tạng & 2 & 6,3 \\
\hline Tràn dịch màng tim & 2 & 6,3 \\
\hline
\end{tabular}

Các biến chứng sau mổ hay gặp nhất là chảy máu phải mổ lại, tai biến mạch máu não và suy thận. Có 4 BN tử vong (12,5\%), 3 BN sau mổ lóc ĐMC, 1 BN phồng ĐMC mổ lại.

Bảng 3.3. Liên quan các yếu tố nguy cơ đến tử vong sớm sau mổ

\begin{tabular}{|c|c|c|c|c|c|}
\hline & & $\mathbf{N}$ & Tử vong & OR & p (Fisher exact) \\
\hline \multirow{2}{*}{ Giới } & Nam & 22 & 1 & \multirow{2}{*}{9} & \multirow{2}{*}{0,079} \\
\hline & Nữ & 10 & 3 & & \\
\hline \multirow{2}{*}{ Mổ cũ } & Có & 4 & 1 & \multirow{2}{*}{2,78} & \multirow{2}{*}{0,43} \\
\hline & Không & 28 & 3 & & \\
\hline \multirow{2}{*}{ Thể bệnh } & Lóc & 17 & 3 & \multirow{2}{*}{3} & \multirow{2}{*}{0,35} \\
\hline & Phồng & 15 & 1 & & \\
\hline \multirow{2}{*}{ PT Quai } & Có & 7 & 4 & \multirow{2}{*}{-} & \multirow{2}{*}{0,00097} \\
\hline & Không & 25 & 0 & & \\
\hline \multirow{2}{*}{$T G C E C \geq 240 p h$} & Có & 3 & 2 & \multirow{2}{*}{27} & \multirow{2}{*}{0,035} \\
\hline & Không & 29 & 2 & & \\
\hline \multirow{2}{*}{$T B M M N$ sau mổ } & Có & 6 & 4 & \multirow[b]{2}{*}{ - } & \multirow{2}{*}{0,030} \\
\hline & Không & 26 & 0 & & \\
\hline
\end{tabular}

Khi kiểm tra các yếu tố liên quan, thấy rằng $\mathrm{PT}$ vùng quai thời gian chạy máy quá 4 tiếng,có TBMMN sau mổ là những yếu tố nguy cơ tử vong có ý nghĩa.

\section{BÀN LUẬN}

\section{1.Đặc điểm trước mổ}

\subsubsection{Tuổi, giới}

Tuổi trung bình trong nghiên cứu của chúng tôi là $52,8 \pm 14,1$, trong đó nhỏ nhất là 31 tuổi, lớn nhất là 79 tuổi. Nam giới chiếm $68,8 \%$. Kết quả về tuổi và giới của chúng tôi cũng tương tự như các tác giả trongvà ngoài nước[1-4].

\subsection{2. Đặc điểm lâm sàng}

Đau ngực là triệu chứng phổ biến ở những BN lóc động mạch chủ, 15/17 (88,2\%), đây cũng là lý do khiến $\mathrm{BN}$ nhập viện. Trong khi đó, dấu hiệu này chỉ có trong 33,3\% BN phồng ĐMC. Tỷ lệ triệu chứng đau ngực trong nghiên cứu của chúng tôi cũng tương tự của các tác giả Nguyễn Thái An và Nguyễn Hữu Ước lần lượt là $82,5 \%$ và $89,5 \%$. Đau ngực trong lóc ĐMC là do mạch 
máu khi bị lóc giãn căng đột ngột, với cường độ mạnh và liên tục[5]. Dấu hiệu này chỉ chiếm $1 / 3$ số trường hợp trong bệnh lý phồng ĐMC, tính chất đau ngực của nhóm bệnh này cũng khác, mức độ ít hơn và diễn biến mạn tính[6]

Hở van ĐMC nhiều trước mổ có $14 \mathrm{BN}$, trong đó 8 trường hợp phồng $\mathrm{DMC}$ lên kèm theo $(53,3 \%)$ và 6 trường hợp trong lóc ĐMC $(35,3 \%)$. Hẹp khít van ĐMC vôi hóa có $1 \mathrm{BN}$. Tổn thương hở chủ trong nhóm bệnh lý này thường do cơ chế giãn tại gốc ĐMC, các lá van trong đa số trường hợp tương đối bình thường. Tỷ lệ hở van ĐMC trong nghiên cứu của chúng tôi cũng tương tự như các tác giả khác[1-2]

Tràn dịch màng ngoài tim số lượng nhiều gặp 7/17 BN lóc ĐMC (41,2\%). Trong lóc ĐMC type $\mathrm{A}$ cấp tính, máu thấm từ thành ĐMC vào khoang màng ngoài tim gây tràn dịch màng tim, chỉ có 1 $\mathrm{BN}$ thực sự có biến chứng vỡ ĐMC gây chèn ép tim cấp, sốc tụt huyết áp trước mổ.

\subsection{3. Đặc điểm tổn thương bệnh lý}

Trong nghiên cứu của chúng tôi, tỷ lệ bệnh nhân có hội chứng Marfan 9/32 (28,1\%), trong đó $6 \mathrm{BN}$ được mổ do phồng gốc $\mathrm{ĐMC}$, hở chủ nặng, $3 \mathrm{BN}$ được mổ do lóc ĐMC.Hội chứng Marfan là rối loạn tổ chức mô liên kết có tính di truyền, phổ biến nhất với tần suất $1 / 10000$ trẻ ra đời sống. Biến chứng động mạch chủ (phồng vỡ, lóc) là biến chứng nặng nhất của bệnh, phát triển rất nhanh ở độ tuổi thanh thiếu niên và là nguyên nhân gây tử vong hàng đầu của bệnh nhân Marfan dưới 40 tuổi nếu không được phẫu thuật kịp thời [7].

Tỷ lệ mổ lại trong nghiên cứu của chúng tôi là $4 / 32$ trường hợp chiếm $12,5 \%$.Cá biệt có 1 bệnh nhân mổ lần thứ 3 , lần 1 cách 6 năm, thay van ĐMC, sửa van hai lá, sau mổ bị viêm nội tâm mạc nhiễm khuẩn van hai lá, được mổ lần 2 để thay van hai lá, lần cuối vào viện để phẫu thuật vì giả phồng ĐMC lên. Mổ lại trong bệnh lý ĐMC là phẫu thuật rất nặng, thời gian mổ kéo dài, nhiều biến chứng và tỷ lệ tử vong gấp đôi so với phẫu thuật ĐMC mổ lần đầu[]].

\section{2. Đặc điểm trong mổ}

Tất cả $32 \mathrm{BN}$ trong nghiên cứu đều được phẫu thuật với tuần hoàn ngoài cơ thể, chủ yếu sử dụng đường ca-nuyn động mạch đùi $(71,9 \%)$, bảo vệ cơ tim bằng máu ấm xuôi dòng $(54,8 \%)$ hoặc ngược dòng $(45,2 \%)$, với những trường hợp phẫu thuật quai ĐMC chúng tôi sử dụng cách thức bảo vệ não xuôi dòng 2 bên.

Về cách thức làm miệng nối, những trường hợp phồng ĐMC, sau khi đã cắt hết đoạn mạch bệnh lý đến tổ chức lành, chúng tôi tiến hành khâu vắt 1 lớp thông thường giữa đoạn mạch nhân tạo với mạch của bệnh nhân. Những trường hợp ĐMC bị lóc hoặc tổ chức mạch rất vôi và mủn, chúng tôi sử dụng kỹ thuật bánh kẹp (sandwich) với 2 dải đệm (bằng mạch nhân tạo) bọc mặt trong và ngoài ĐMC để gia cố miệng nối trước khi khâu với đoạn mạch nhân tạo. Với những miệng nối nhỏ (gốc ĐM vành), thay vì sử dụng dải đệm bằng mạch nhân tạo, chúng tôi sử dụng dải màng tim của bệnh nhân để gia cố miệng nối.

\subsection{Kết quả sớm sau mổ}

\subsubsection{Biến chứng sớm sau mổ}

Biến chứng hay gặp nhất trong nghiên cứu của chúng tôi là chảy máu phải mổ lại và tai biến mạch não chiếm tỷ lệ ngang nhau là $18,8 \%$. Trong nghiên cứu của tác giả Nguyễn Hữu Ước cũng cho biết chảy máu là biến chứng hay gặp nhất sau mổ lóc ĐMC[1]. Tỷ lệ chảy máu mổ lại trong nghiên cứu của Nguyễn Thái An là 12,5\%[2], của Nguyễn Văn Mạnh(MontpellierPháp) là $10,1 \%[\underline{3}]$. Tỷ lệ chảy máu phải mổ lại trong nghiên cứu của Judson $\mathrm{B}$. Williams (Bắc Mỹ) là $10 \%$ với mổ phiên và $14,2 \%$ với mổ cấp cứu[4]. Tỷ lệ chảy máu sau mổ của chúng tôi cao hơn các tác giả khác, nguyên nhân do chúng tôi chưa có nhiều kinh nghiệm trong phẫu thuật phồng, lóc ĐMC, các phương tiện để tăng khả năng cầm máu như keo sinh học và dải đệm ĐMC chuẩn không sẵn có. Tuy nhiên, không có $\mathrm{BN}$ nào tử vong do chảy máu. 
Tỷ lệ tai biến mạch máu não (TBMMN) gặp $18,8 \%$, chủ yếu là thể nhồi máu $(5 \mathrm{BN}), 1 \mathrm{BN}$ xuất huyết não (ngày thứ 10 sau mổ). 4/6 $\mathrm{BN}$ tử vong do tai biến mạch máu não, $1 \mathrm{BN}$ nhồi máu tiểu não mức độ ít, sau quá trình điều trị chỉ còn loạn thần nhẹ, $1 \mathrm{BN}$ nhồi máu nảo rải rác 2 bán cầu cũng không để lại di chứng khi ra viện. Như vậy, tổn thương não để lại di chứng vĩnh viễn là 4/ trường hợp (12,5\%). Tỷ lệ tai biến mạch não trong nghiên cứu của chúng tôi còn cao so với các tác giả trong và ngoài nước. Tác giả Nguyễn Thái An, cho biết tỷ lệ biến chứng thần kinh vĩnh viễn trong nghiên cứu của mình là $4,2 \%$. Judson Williams, báo cáo tổn thương não gặp 6,2 \%.

\subsubsection{Tử vong sớm sau mổ}

Không có $\mathrm{BN}$ nào tử vong trên bàn mổ do chảy máu hay suy tim cấp sau ngừng máy tim phổi nhân tạo.Tỷ lệ tử vong trong bệnh viện của chúng tôi là $12,5 \%$.Trong 4 trường hợp tử vong, 3 trường hợp lóc $\mathrm{ĐMC}, 1$ trường hợp phồng $\mathrm{ĐMC}$ mổ lại, đều là những thể bệnh rất nặng. Nguyên nhân tử vong đều khởi đầu do tổn thương não, và tất cả đều có phẫu thuật thay quai ĐMC (toàn bộ hoặc một phần)do đó rất dễ tổn thương các ĐM nuôi não. Tỷ lệ từ vong trong nghiên cứu của tác giả Nguyễn Văn Mạnh là $25,5 \%$ và nguyên nhân do tổn thương não và suy đa tạng [3]; trong nghiên cứu của Nguyễn Hữu Ước, tử vong chiếm $20,8 \%$ với nguyên nhân chính là suy tim cấp sau mổ và suy đa tạng [1]. Judson Williams (Bắc Mỹ), báo cáo về các phẫu thuật gốc ĐMC cho biết, tử vong trong bệnh viện chiếm 8,3\% [4]. Khi kiểm tra các yếu tố liên quan, thấy rằng thời gian chạy máy quá 4 tiếng, giới tính nữ, có phẫu thuật quai ĐMC, TBMMN sau mổ là những yếu tố nguy cơ tử vong có ý nghĩa.

\section{KẾT LUẬN}

Phẫu thuật điều trị bệnh lý phồng và lóc ĐMC là phẫu thuật nặng với tỷ lệ biến chứng và tử vong cao. Tại Bệnh viện Tim Hà nội, mới triển khai nhiều những phẫu thuật này trong vòng 3 năm trở lại đây. Tuy nhiên kết quả phẫu thuật rất khả quan với tỷ lệ tử vong $12,5 \%$. Nữ giới, phẫu thuật quai ĐMC, thời gian chạy máy quá 4 tiếng, TBMMN sau mổ là những yếu tố nguy cơ tử vong có ý nghĩa.

\section{TÀI LIỆU THAM KHẢO}

1. Nguyễn Hữu Ước và Vũ Ngọc Tú (2013). Đánh giá kết quả phẫu thuật lóc động mạch chủ type A tại Bệnh viện Việt Đức. Tạp chí phẫu thuật Tim mạch và Lồng ngực Việt Nam, 4, 59-65.

2. Nguyễn Thái An và Phạm Thọ Tuấn Anh (2010). Đánh giá kết quả sớm phẫu thuật phình và bóc tách động mạch chủ lên và quai. Tạp chí Y học Việt Nam, 375, 77-82.

3. Manh Nguyen Van, R. Demaria, J.M. Frapier và cộng sự (2008). Ré sultat de la chirurgie des dissections aigues de l'aorte thoracique ascendente à propos de 141 cas. Société francais decChirurgie Thoracique et cardio vasculaire, 12, 21-27.

4. Judson B. Williams, Eric D. Peterson, Yue Zhao và cộng sự (2012). Contemporary Results for Proximal Aortic Replacement in North America. J Am Coll Cardiol, 60(3), 1156-1162.

5. J. Bachet (2004). Dissections aiguës de l'aorte : physiopathologie et diagnostic. EMCChirurgie, 1(301-323),

6. Derek R. Brinster và Robert J. Rizzo (2008). Ascending Aortic Aneurysms. Cardiac Surgery in the Adult, The McGraw-Hill Companies, 1, 1223-1250.

7. D. E. Cameron và L. A. Vricella (2005). Valve-Sparing Aortic Root Replacement in Marfan Syndrome. pediatric cardiac surgery annual, 8, 103-111.

8. Thai Minh Nguyen, Nicolas D'Ostrevy, Lionel Camilleri và cộng sự (2013). Résutat à moyen terme de la chirurgie de remplacement de l'aorte ascendent redux. Société francais de Chirurgie Thoracique et cardio - vasculaire, 17(3), 157-163. 